\title{
sciendo
}

\section{Haloperidol and aripiprazole impact on the BDNF and glucocorticoid receptor levels in the rat hippocampus and prefrontal cortex: effect of the chronic mild stress}

\author{
Jana Osack A ${ }^{1}$, Romana Koprdova ${ }^{2}$, Andrej Tillinger ${ }^{1}$, Zdenko Pirnik ${ }^{1,3,4}$, Alexander Kiss ${ }^{1}$
}

\begin{abstract}
${ }^{1}$ Institute of Experimental Endocrinology, Biomedical Research Center, Slovak Academy of Sciences, Bratislava, Slovakia; ${ }^{2}$ Institute of Experimental Pharmacology and Toxicology, Centre of Experimental Medicine, Slovak Academy of Sciences, Bratislava, Slovak Republic; ${ }^{3}$ Institute of Physiology, Faculty of Medicine, Comenius University in Bratislava, Bratislava, Slovak Republic; ${ }^{4}$ Institute of Organic Chemistry and Biochemistry of the Czech Academy of Sciences, Prague, Czech Republic E-mail: jana.bundzikova@savba.sk
\end{abstract}

Objective. Changes in the brain derived neurotrophic factor (BDNF) and glucocorticoid receptor (GR) expression in the prefrontal cortex (PFC) and hippocampus (HIP) are associated with psychiatric diseases and stress response. Chronic mild stress (CMS) may alter BDNF as well as GR levels in both the PFC and the HIP. The aim of the present study was to find out whether chronic treatment with a typical antipsychotic haloperidol (HAL) and an atypical antipsychotic aripiprazole (ARI) may modify the CMS effect on the BDNF and GR expression in the above-mentioned structures.

Methods. The rats were exposed to CMS for 3 weeks and from the $7^{\text {th }}$ day of CMS injected with vehicle (VEH), HAL (1 mg/kg) or ARI (10 mg/kg) for 4 weeks. BDNF and GR mRNA levels were established in the PFC and the HIP by Real Time PCR, whereas, PFC and HIP samples were obtained by punching them from $500 \mu \mathrm{m}$ thick frozen sections. C-Fos immunoreactivity was analyzed in the PFC and the HIP on $30 \mu \mathrm{m}$ thick paraformaldehyde fixed sections. Weight gain and corticosterone (CORT) levels were also measured.

Results. The CMS and HAL suppressed the BDNF and GR mRNA levels in the PFC. In the HIP, CMS elevated BDNF mRNA levels that were suppressed by HAL and ARI treatments. The CMS decreased the c-Fos immunoreactivity in the PFC in both HAL- and ARI-treated animals. In the HIP, HAL increased the c-Fos immunoreactivity that was again diminished in animals exposed to CMS. Stressed animals gained markedly less weight until the $7^{\text {th }}$ day of CMS, however, later their weight gain did not differ from the unstressed ones or was even higher in CMS+HAL group. Unstressed HAL and ARI animals gained less weight than the VEH ones. Neither CMS nor HAL/ARI affected the plasma CORT levels.

Conclusion. The present data indicate that HAL and ARI in the doses $1 \mathrm{mg} / \mathrm{kg}$ or $10 \mathrm{mg} / \mathrm{kg}$, respectively, does not modify the effect of the CMS preconditioning on the BDNF and GR mRNA levels in the PFC or the HIP. However, HAL seems to modify the CMS effect on the HIP activation.

Key words: brain derived neurotrophic factor, glucocorticoid receptors, c-Fos-immunohistochemistry, haloperidol, aripiprazole, prefrontal cortex, hippocampus, rat

\footnotetext{
Corresponding author: Jana Osacka, PhD., Biomedical Research Center, Institute of Experimental Endocrinology, Slovak Acad-
} emy of Sciences, Dubravska cesta 9, 84505 Bratislava, Slovakia; phone: +421-2-32295214; e-mail: jana.bundzikova@savba.sk. 
Antipsychotics are a class of medicaments primarily used in the psychosis treatment and as an adjunctive therapy in patients with major depression (Mulder et al. 2018). The common feature of the antipsychotics resides in their effect on the dopaminergic system. Haloperidol (HAL) is considered as a typical or the first-generation antipsychotic and clinical trials pointed to its beneficial effect on the positive symptoms of schizophrenia (Tyler et al. 2017). Aripiprazole (ARI) represents a prototype of the third-generation of antipsychotics that are distinguished by their agonist pharmacology at certain receptor targets, most notably dopamine D2 autoreceptors what reflects their efficacy for treatment of positive, negative, and cognitive symptoms of schizophrenia with reduced side effects. There is a substantial evidence that both the typical and the atypical antipsychotics can suppress the basal as well as stimulated hypothalamus-pituitary-adrenal (HPA) axis activity. Acute as well as chronic/repeated treatments with typical and atypical antipsychotics have been shown to reduce cortisol levels in humans (Jacobson 2014) and modify the reactivity of selected brain structures to stress (Osacka et al. 2018).

The chronic mild stress (CMS) is an animal model, which has been developed to mimic the relatively minor and unanticipated irritations of the human everyday life (Kompagne et al. 2008). It is considered to be an effective rodent depression model consisting of a repeated exposure to several varying and unpredictable mild stressors over a sustained period of time (ranging from 10 days to 8 weeks). Its effect may persist up to 3 months (Willner 1997; Hill et al. 2012; Antoniuk et al. 2019) and it is effective in inducing behavioral and neurobehavioral disturbances (Kompagne et al. 2008) evoked by changes at the level of different neurotransmitters and their receptors (Hill et al. 2012).

Changes in brain derived neurotrophic factor (BDNF) expression are connected to psychiatric diseases associated with memory processes in the hippocampus (HIP) and also to stress-induced changes in the glococorticoid receptor (GR) levels in the prefrontal cortex (PFC). Actually, the HIP-PFC circuit that is linked with cognitive and emotional disturbances in several psychiatric disorders, has been shown to be highly sensitive to stress (Godsil et al. 2013). High proportion of depressed individuals has been shown to exhibit glucocorticoid hypersecretion (Parker et al. 2003) what has been supported also in animal studies (Ayensu et al. 1995). Consistent with the elevated corticosterone (CORT) level, decreased GR levels downregulation has been reported in the
HIP or the frontal cortex after CMS exposure (Froger et al. 2004; Pan et al. 2010). Neurotrophins, including BDNF, play an undebatable role in the etiology and treatment of depression. Data concerning the effect of CMS on BDNF levels are inconsistent. Within the whole HIP, the CMS reduced BDNF mRNA (Nibuya et al. 1999; Song et al. 2006; Mao et al. 2009), but this effect disappeared when HIP subregions were analyzed (Hill et al. 2012). Concerning the PFC, the CMS has been shown to decrease or exert no effect on BDNF levels (Zhang et al. 2010).

The aim of the present study was to find out whether chronic treatment with typical antipsychotic HAL or atypical antipsychotic ARI may modify the CMS effect on the BDNF and GR mRNA expression in the PFC and the HIP.

\section{Materials and methods}

Animals. Male Sprague Dawley rats $(n=65), 7-9$ weeks old (weighing 270-290 g), purchased from Charles River (Germany) were used. They were housed 3-4 per cage in an animal facility with controlled temperature $\left(22 \pm 1^{\circ} \mathrm{C}\right), 12$-h light/dark cycle (lights on at 06:00 a.m.) and humidity 55\%. The animals were provided with a regular rat chow (dry pellets) and tap water ad libitum. Principles of the Laboratory Animal Care and the experimental procedures used were approved by the State Veterinary and Food Administration of the Slovak Republic Committee (Approval protocol number 1461/17-221) in accordance with the Council Directive 2010/63EU of the European Parliament and the Council of September 22, 2010 on the protection of animals used for scientific purposes.

Experimental design. The rats were acclimatized to the new conditions 9-days prior the experimental procedure initiation. According to the experimental conditions, the animals were divided into two groups: unstressed controls and exposed to CMS. Each group was further subdivided into vehicle (VEH, $\mathrm{n}=10$; CMS+VEH, $\mathrm{n}=11$ ), haloperidol (HAL, $\mathrm{n}=11$; CMS+HAL, $n=11)$ and aripiprazole treated ones (ARI, $\mathrm{n}=11, \mathrm{CMS}+\mathrm{ARI}, \mathrm{n}=11$ ). The CMS consisted of six stress episodes: overcrowding [7-8 instead of 3-4 rats were placed into the cage T4 $(590 \times 380 \times 200 \mathrm{~mm}$ of size) for $24 \mathrm{~h}$ ], air-puff (air noise divided into 45 episodes, each of them lasting $1 \mathrm{~min}$, randomized by a computer for $24 \mathrm{~h}$ ), wet bedding (1000 $\mathrm{ml}$ of water poured into the cage for $24 \mathrm{~h}$ ), predator stress $(5 \times 5 \times 10 \mathrm{~cm}$ large perforated box filled with cats litter box content was put into the home cage for $24 \mathrm{~h}$ to provide cat odor), forced swimming (immersion of the rats in a $45 \mathrm{~cm}$ tall and $25 \mathrm{~cm}$ wide glass cylinder 
filled with $24 \pm 1^{\circ} \mathrm{C}$ water for $10 \mathrm{~min}$ ) and food deprivation (food withdrawal for $24 \mathrm{~h}$ ). The CMS animals received daily one of 6 stressors in variable order for 3 weeks. Since the $7^{\text {th }}$ day of the CMS, the animals were intraperitoneally (i.p.) injected daily with VEH (10\% DMSO in water, $0.1 \mathrm{ml} / 100 \mathrm{~g}$ of the body weight), HAL ( $1 \mathrm{mg} / \mathrm{kg}$, dissolved in VEH) or ARI (10 mg/kg, dissolved in $\mathrm{VEH}$ ) during the next 28 days (Figure 1). During the experiment, the animals were regularly handled and weighed.

Tissue processing. Four animals from each experimentalgroupweresacrificed by transcardial perfusion. The rats were anesthetized by a combination of tiletamine-zolazepam (Zoletil, $30 \mathrm{mg} / \mathrm{kg}$, Virbac, Carros, France) and xylazine (Xylariem, $15 \mathrm{mg} / \mathrm{kg}$, Riemser Germany) in the volumes $0.1 \mathrm{ml}$ and $0.24 \mathrm{ml} / 300 \mathrm{~g} /$ body weight and afterwards transcardially perfused with $60 \mathrm{ml}$ of saline containing $450 \mu \mathrm{l}$ of heparin (5000 IU/l, Zentiva, Slovakia) followed by $250 \mathrm{ml}$ of fixative containing $4 \%$ paraformaldehyde (SigmaAldrich, Germany) in $0.1 \mathrm{M}$ phosphate buffer (PB, $\mathrm{pH}$ 7.4). Removed brains were postfixed in a fresh fixative overnight, washed two times in $0.1 \mathrm{M} \mathrm{PB}$, infiltrated with $30 \%$ sucrose for 2 days at $4{ }^{\circ} \mathrm{C}$, cut into $30 \mu \mathrm{m}$ thick coronal sections using cryocut (Reichert\&Jung, Germany), collected in a cryoprotectant solution and stored at $-20^{\circ} \mathrm{C}$. These sections were used for the immunohistochemical processing. The rest of the animals was decapitated and their brains were quickly removed, frozen on dry ice, and kept in freezer at $-75^{\circ} \mathrm{C}$. Immediately after decapitation, the trunk blood was collected in polyethylene tubes containing EDTA ( $1 \mathrm{mg} / \mathrm{ml}$ blood) and centrifuged at $1000 \times \mathrm{g}$ for $20 \mathrm{~min}$ at $4{ }^{\circ} \mathrm{C}$. Separated plasma was stored at $-20^{\circ} \mathrm{C}$ until analysis. Plasma CORT levels were measured by ELISA kit (ADI-900-097, ENZO) according to the manufacturer's instructions.

c-Fos immunohistochemistry. For the immunohistochemistry, brain sections used were selected based on the following coordinates: PFC (3.72$2.76 \mathrm{~mm}$ from Bregma) and HIP $(-3.48--4.2 \mathrm{~mm})$ (Paxinos and Watson 2007). All the sections were repeatedly washed in cold $0.1 \mathrm{M} \mathrm{PB}$ and preincubated in a blocking solution containing $0.3 \% \mathrm{H}_{2} \mathrm{O}_{2}$ in 0.1 M PB (Fisher Scientific, NJ, USA) for $20 \mathrm{~min}$ at room temperature (RT). Then the sections were rinsed $3 \times 10 \mathrm{~min}$ in $0.1 \mathrm{M} \mathrm{PB}$ and incubated with a rabbit monoclonal c-Fos antibody diluted 1:2000 in 0.1 M $\mathrm{PB}$ containing 4\% normal goat serum (Gibco, NY, USA), 0.5\% Triton X-100 (Koch-Light Lab. Ltd., UK), and $0.1 \%$ sodium azide (Sigma Chemical Ltd., MO, USA) for $48 \mathrm{~h}$ at $4^{\circ} \mathrm{C}$. After several rinsing in $\mathrm{PB}$, the sections were incubated with biotinylated goat anti- rabbit IgG (1:500) in PB for $90 \mathrm{~min}$ at RT. Next PB rinsing was followed by incubation with the avidinbiotin peroxidase complex (1:250) for $90 \mathrm{~min}$ at RT. After several washings in $0.05 \mathrm{M}$ sodium acetate buffer (SAB, pH6.0), c-Fos antigenic sites were visualized by nickel-enhanced 3,3'-diaminobenzidine tetrahydrochloride $(0.0625 \% \mathrm{DAB}, 2.5 \%$ nickel chloride, Sigma-Aldrich, No. 7718-54-9), in SAB containing $0.0006 \%$ hydrogen peroxide. Developing time was $10 \mathrm{~min}$. The heavy metal-intensification of DAB yielded black staining in the Fos labelled nuclei.

Microdissection of brain areas. The gene expression levels were measured in the PFC and the HIP areas dissected from the frozen brain tissues. Brains kept at $-75^{\circ} \mathrm{C}$ were acclimatized to $-12^{\circ} \mathrm{C}$ in a cryostat (Reichert\&Jung, Germany) and sliced into 500 $\mu \mathrm{m}$ thick coronal sections. The brain areas PFC $($ Bregma $=3.2 \mathrm{~mm})$ and HIP (Bregma $=-3.8 \mathrm{~mm}$ ) were selected based on Paxinos and Watson (2007) brain atlas and microdissected from the frozen sections by a punch technique (Palkovits and Brownstein 1988) under stereomicroscope using a dissection needle with the $1 \mathrm{~mm}$ of inner diameter. The dissected pieces of the brain tissue were collected in Eppendorf tubes, frozen in liquid nitrogen, and stored at $-75^{\circ} \mathrm{C}$ until analyzed.

RNA isolation and Real Time PCR. Total RNA was isolated using the TRI ReagentÒRT (MRC, Inc., USA) according to the manufacturers' protocol and concentration was quantified using the NanoDrop 2000 (Thermo Fisher Scientific, USA). Reverse transcription of RNA (300 ng from each brain nucleus) was performed with the RevertAid $H$ minusFirst Strand cDNA Synthesis kit (Thermo Fisher Scientific, USA) according to the manufacturer's protocol, using an oligo dT primer. Semi-quantitative Real Time PCR was set up in total volume of $25 \mu$ l containing 30 ng of template cDNA mixed with $12.5 \mu$ l of FastStart Universal SYBR Green Master Rox (Roche Diagnostics, Switzerland), $1 \mu$ l of specific primer pair set and water. Sequences of specific primers used are provided in Table 1. Each sample was analyzed on QuantStudio 5 Real-Time PCR System (Applied Biosystems, USA) under the following conditions: 1 cycle of $2 \mathrm{~min}$ at $50^{\circ} \mathrm{C}$ followed by 1 cycle of $10 \mathrm{~min}$ at $95^{\circ} \mathrm{C}$ and then 40 cycles of $95^{\circ} \mathrm{C}$ for $15 \mathrm{~s}$ and $60^{\circ} \mathrm{C}$ for $1 \mathrm{~min}$. Data are normalized to GAPDH levels and expressed as the relative fold change, calculated using the DDCt method (Livak and Schmittgen 2001). Melting curve analysis was performed to confirm the specificity of the amplified products.

Antibodies. The primary monoclonal rabbit anti-c Fos antibody [c-Fos (9F6) Rabbit mAb \#2250] was 
Table 1

List of the specific primer (BDNF, GR, and GAPDH) sequences used in the PCR procedure

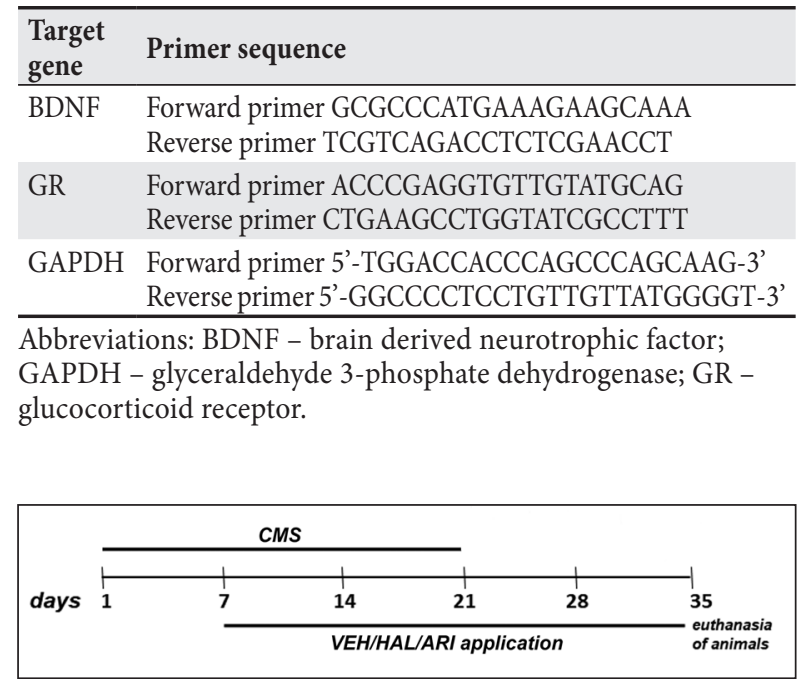

Figure 1. Time schedule of the experimental procedure. The stressed animals were exposed to chronic mild stress (CMS) for 21 days. Since the $7^{\text {th }}$ day of the CMS, the stressed and unstressed animals were daily i.p. injected with vehicle (VEH), haloperidol (HAL) or aripiprazole (ARI) for 28 days. Animals were sacrificed on the $35^{\text {th }}$ day of the experiment.

purchased from Cell Signaling Technology Inc. The biotinylated goat anti-rabbit IgG (VectorStain Elite ABC Kit) was purchased from Vector Lab., CA, USA.

Statistical analysis. All the data were analyzed with SigmaPlot 11.0 software (Systat Software, Inc.). Normal distribution of obtained data was checked by Shapiro-Wilks test. If groups were not with homogeneous variance square root transform was applied. Weight gain on the $7^{\text {th }}$ day was analyzed by Student's T-test and for all other analyses, two-way ANOVA followed by Fisher's LSD post-hoc test was used. Data are reported as mean \pm standard error of mean (SEM). Differences were considered significant at $\mathrm{p}<0.05$. The outliers were excluded if the data points ranged more than 1.5 interquartile below the first quartile or above the third quartile.

\section{Results}

Weight gain. To verify the CMS effectiveness, the weight of animals was measured after the first week of the CMS ( $7^{\text {th }}$ day of the experiment), $3^{\text {rd }}$ week of the CMS, i.e., CMS termination $\left(21^{\text {st }}\right.$ day of the experiment) and 2 weeks after the cessation of the CMS ( $35^{\text {th }}$ day of the experiment) (Figure 2). Since until the $7^{\text {th }}$ day, the animals were not injected with treatment, the weight gain was measured in the $1^{\text {st }}$ interval only in the unstressed and CMS animals. On the $7^{\text {th }}$ day of the experiment, the CMS rats had significantly lower weight gain than the unstressed ones $[\mathrm{t}(62)=19.2$; $\mathrm{p}<0.001$; Figure 2]. At the end of the CMS, i.e., $21^{\text {st }}$ day of the experiment, two-way ANOVA found significant effect of the CMS on the weight gain of the animals $[F(1,36)=15.36 ; p<0.001$; Figure 2]. Unstressed HALtreated animals had less weight gain than the $\mathrm{VEH}$ and CMS+HAL ones $(p=0.02 ; p<0.001$; Figure 2$)$. On the $35^{\text {th }}$ day of the experiment, the statistical analysis detected influence of the conditions $[\mathrm{F}(1,63)=12.68$; $\mathrm{p}<0.001)$, treatment $[\mathrm{F}(2,63)=3.23 ; \mathrm{p}=0.047]$ and their interaction $[\mathrm{F}(2,63)=6.85 ; \mathrm{p}=0.002]$ on the animals weight gain. Unstressed HAL- and ARI-treated animals gained less weight than the $\mathrm{VEH}$ ones $(\mathrm{p}=0.024$ and $\mathrm{p}=0.049$; Figure 2$) . \mathrm{CMS}+\mathrm{HAL}$ rats had markedly increased weight gain in comparison with the HAL, CMS+VEH, and CMS+ARI experimental groups $(\mathrm{p}<0.001 ; \mathrm{p}=0.009 ; \mathrm{p}<0.001$, respectively; Figure 2).

Brain-derived neurotrophic factor (BDNF). In the PFC, the statistical analysis revealed effect of experimental conditions $[\mathrm{F}(1,45)=7.78 ; \mathrm{p}=0.035]$ on BDNF mRNA levels. In unstressed animals, only HAL treatment suppressed BDNF mRNA level in comparison with the VEH ones $(p=0.028$; Figure 3, left). Besides, the CMS decreased BDNF gene expression only in the VEH-treated animals $(\mathrm{p}=0.012$; Figure 3, left). ARI application did not influence BDNF levels in the PFC.

In the HIP, the statistical analysis showed effect of experimental conditions $[\mathrm{F}(1,45)=4.07 ; \mathrm{p}=0.05]$ and treatment $[\mathrm{F}(2,45)=4.91 ; \mathrm{p}=0.012]$ on BDNF mRNA levels. The CMS elevated BDNF mRNA level in the HIP in the VEH-treated animals $(p=0.007$; Figure 3, left). While in unstressed animals, the antipsychotic treatment did not modify BDNF mRNA levels; in the CMS animals, both antipsychotics, HAL $(\mathrm{p}<0.00$; Figure 3, left) and ARI ( $p=0.036$; Figure 3, left) significantly reduced BDNF mRNA levels in comparison with the CMS+VEH ones.

Glucocorticoid receptors (GR). In the PFC, two-way ANOVA showed significant effect of the experimental conditions $[\mathrm{F}(1,45)=4.29 ; \mathrm{p}=0.045]$. HAL treatment in unstressed animals and CMS exposure in VEH animals suppressed GR expression when compared with the unstressed VEH ones $(\mathrm{p}=0.012$ and $\mathrm{p}=0.003$, respectively; Figure 3, right). ARI treatment did not modify GR level in the PFC. In the HIP, no effect of treatment or CMS exposure on GR mRNA levels was observed (Figure 3, right). 


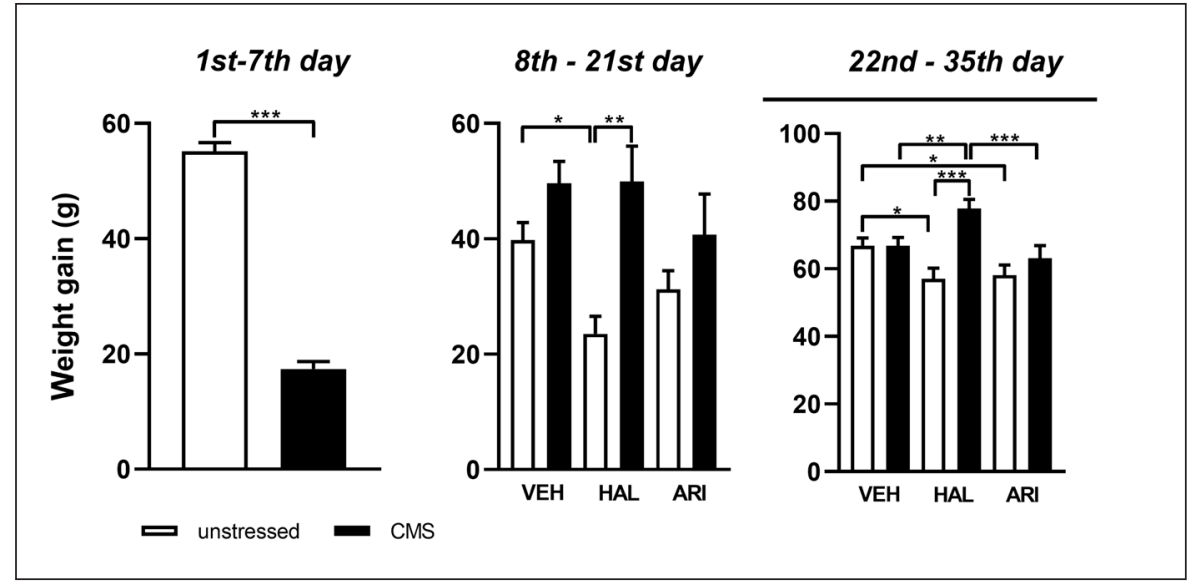

Figure 2. Weight gain of the animals on the $7^{\text {th }}, 21^{\text {st }}$, and $35^{\text {th }}$ day of the experiment. On the $7^{\text {th }}$ day, the CMS significantly suppressed weight gain of the animals. On the $21^{\text {st }}$ day, the CMSexposed animals took on more weight than the unstressed ones. Unstressed HAL-treated rats exhibited lower weight gain than the VEH and CMS+HAL ones. Two weeks after the CMS termination, on the $35^{\text {th }}$ day of the experiment, HAL and ARI treatments decreased the weight gain of the animals compared to the VEH ones. CMS+HAL rats took on more weight than the HAL, CMS+VEH and CMS+ARI ones. Data are presented as the mean \pm SEM ( $7^{\text {th }}$ day: $\mathrm{n}=31-33 ; 21^{\text {st }}$ and $35^{\text {th }}$ day: $\left.\mathrm{n}=10-11\right) ;{ }^{*} \mathrm{p}<0.05 ;{ }^{* *} \mathrm{p}<0.01,{ }^{* *} \mathrm{p}<0.001$. Abbreviations: ARI - aripiprazole; CMS - chronic mild stress; HAL - haloperidol; VEH - vehicle.

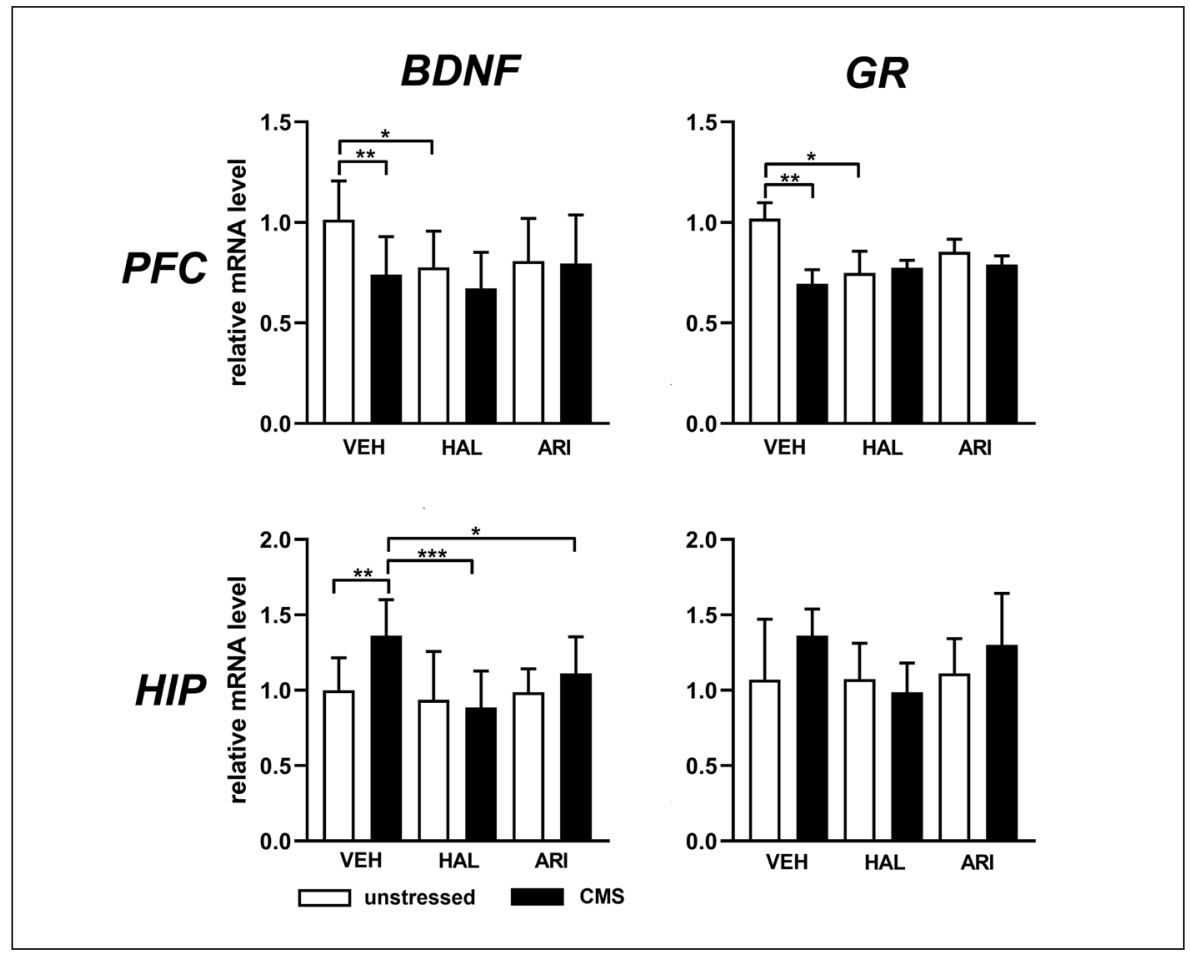

Figure 3. BDNF and GR relative mRNA levels in the PFC and the HIP. In the PFC, the BDNF and GR mRNA levels were suppressed by HAL treatment in unstressed animals and by CMS in the VEH-treated ones. In the HIP, the CMS+VEH experimental group exhibited higher relative BDNF mRNA levels than the VEH, CMS+HAL, and CMS+ARI ones. No change in the GR mRNA levels were detected in the HIP after CMS or HAL/ARI treatment. Data are presented as the mean \pm SEM $\left(n=7-8\right.$ per group); ${ }^{*} p<0.05 ;{ }^{* *} \mathrm{p}<0.01 ;{ }^{* *} \mathrm{p}<0.001$. Abbreviations: ARI - aripiprazole; BDNF - brain derived neurotrophic factor; CMS - chronic mild stress; GR - glucocorticoid receptor; HAL - haloperidol; HIP - hippocampus; PFC - prefrontal cortex; 


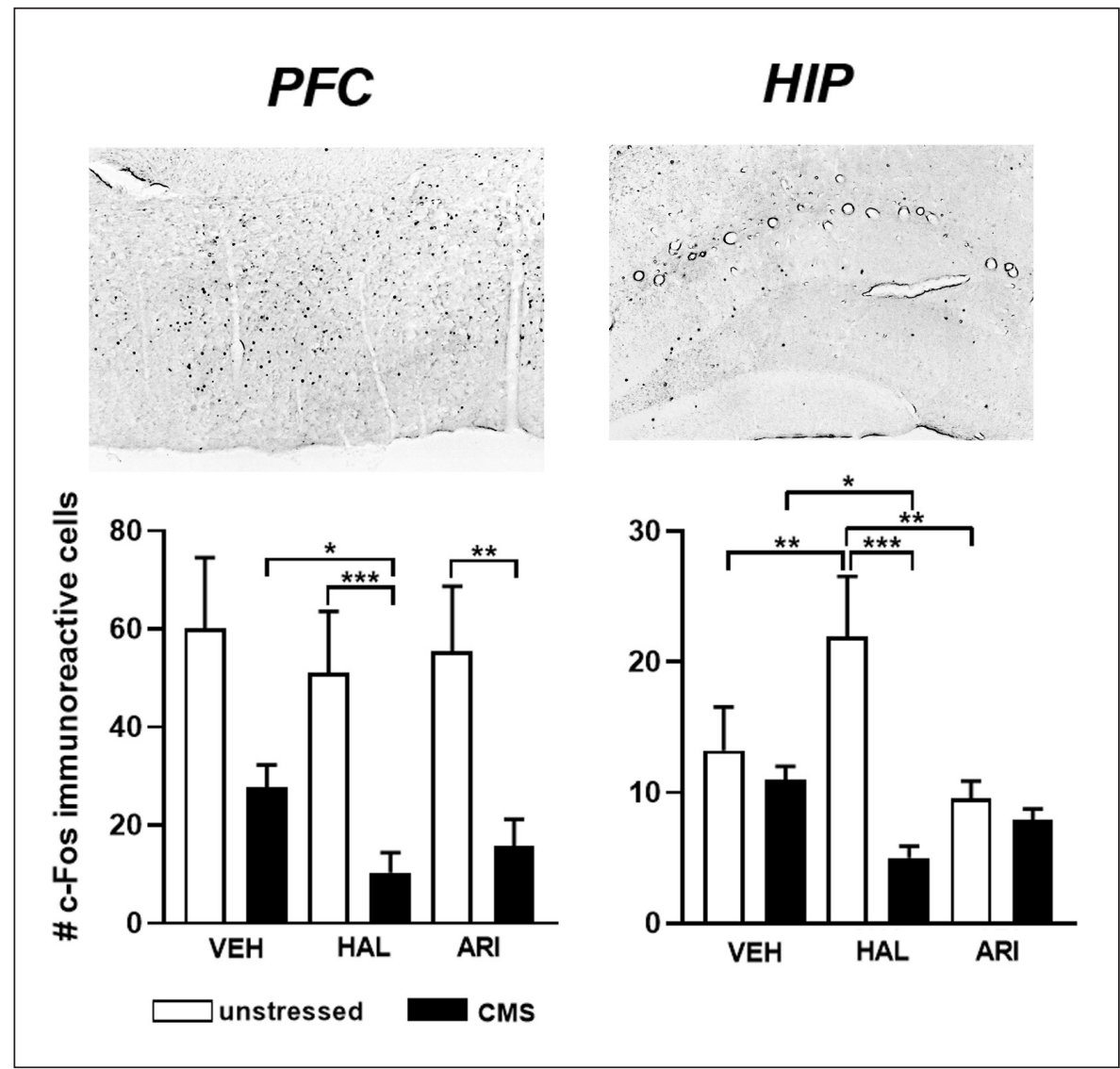

VEH - vehicle.

Figure 4. Activation of PFC (left) and HIP (right) was studied via c-Fos immunoreactivity. In the PFC, the CMS previous exposure significantly reduced the number of c-Fos immunoreactive cells in HAL- and ARI-treated animals and CMS+HAL experimental group showed less c-Fos immunopositive cells than the CMS+VEH one. In the HIP of unstressed animals, HAL treatment increased the number of c-Fos cells in comparison with the VEH and ARI ones and CMS+HAL rats exhibited less c-Fos immunopositive cells than the CMS+VEH and HAL ones. Over the graphs, representative photomicrographs of c-Fos immunostaining in the PFC and HIP are shown. Data are presented as the mean \pm SEM ( $n=14-18$ per group); ${ }^{*}<0.05 ;{ }^{* *} \mathrm{p}<0.01$; ${ }^{* * *} \mathrm{p}<0.001$. Abbreviations: ARI - aripiprazole; CMS - chronic mild stress; HAL - haloperidol;

c-Fos immunohistochemistry. In the PFC, two-way ANOVA showed significant effect of the experimental conditions on the number of $\mathrm{c}$-Fos immunoreactive cells $[\mathrm{F}(1,67)=24.25 ; \mathrm{p}<0.001]$. In unstressed animals, the antipsychotic treatment did not influence number of c-Fos immunopositive cells (Figure 4, left). Although the CMS exposure did not affect the number of c-Fos cells in the VEH-treated rats, it significantly reduced the number of c-Fos cells in the HAL- ( $<<0.001$; Figure 4, left) and ARI-treated ones $(\mathrm{p}=0.001$; Figure 4, left). CMS+HAL experimental group exhibited markedly lower number of c-Fos cells in comparison with the CMS+VEH one $(p=0.036$; Figure 4, left).
In the HIP, two-way ANOVA revealed a significant effect of experimental conditions $[\mathrm{F}(1,97)=7.2$; $\mathrm{p}=0.009$ ] and their mutual interaction with treatment $[\mathrm{F}(2,97)=8.27 ; \mathrm{p}<0.001]$ on the number of $\mathrm{c}-\mathrm{Fos}$ immunoreactive cells. In the unstressed animals, HAL significantly increased the number of c-Fos immunoreactive cells compared to VEH $(\mathrm{p}=0.008)$ and ARI ones ( $\mathrm{p}=0.002$; Figure 4, right). CMS suppressed the number of c-Fos cells in CMS+HAL experimental group compared to the HAL $(p<0.001$; Figure 4, right) and $\mathrm{VEH}+\mathrm{CMS}$ ones ( $\mathrm{p}=0.014$; Figure 4, right).

Plasma corticosterone. Statistical analysis did not reveal significant differences in the plasma CORT levels between the experimental groups (Figure 5). 


\section{Discussion}

The present study showed that the CMS and HAL suppressed the BDNF and GR mRNA levels in the PFC. In the HIP, the CMS elevated BDNF mRNA levels that were suppressed by HAL and ARI treatments. The CMS decreased the c-Fos immunoreactivity in the PFC in both HAL- and ARI-treated animals. In the HIP, HAL increased the c-Fos immunoreactivity that was again diminished by CMS. The stressed animals gained markedly less weight until the $7^{\text {th }}$ day of the CMS; however, later their weight gain has not already differed from the unstressed ones. Unstressed HAL and ARI animals gained less weight than the VEH ones. Neither CMS nor HAL/ ARI affected the plasma CORT levels.

The CMS model is associated with body weight loss as well as a variety of different behavioral paradigms (Willner 1997; Wiborg 2013). Body weight loss is one of the factors, which can be used to monitor the progression of the CMS (Sequeira-Cordero et al. 2019). In the present study, a significant weight decrease was observed only during the first week. Notably, after $1^{\text {st }}$ week of the CMS, the weight gain of the CMS+VEH animals did not differ from the unstressed ones, but their overall weight gain was still lower, what suggests the effectiveness of the CMS model used. Effect of antipsychotics on weight gain has especially been linked to the second-generation of antipsychotics; however, the first-generation of antipsychotics is not completely free of this effect either (Musil et al. 2015). However, lower weight gain was observed in HAL- (on the $21^{\text {st }}$ and $35^{\text {th }}$ day) and ARI-treated animals (on the $35^{\text {th }}$ day). Most of the published data have shown no effect or increase in the weight gain after HAL/ARI treatment. The gender, period of applications, and the dose of the drug used seem to be important factors (Pouzet et al. 2003; Fell et al. 2004; Skrede et al. 2012; De Santis et al. 2014; Musil et al. 2015). HAL-induced body weight gain reduction has been reported not earlier than 4 months after the treatment (Fachinetto et al. 2005). Notably, increased weight gain in the CMS preconditioned HAL-treated animals suggests that HAL may prevent the CMS induced weight loss.

In the brain, the CMS may induce changes in different part of the neuroaxis. The hippocampalprefrontal cortex circuit has been shown to be highly sensitive to stress (Godsil et al. 2013). In the present study, the effect of CMS on the BDNF and GR gene expression was found in the PFC and the HIP. In the $\mathrm{PFC}$, in the VEH-treated animals, CMS preconditioning suppressed both BDNF and GR gene expres-

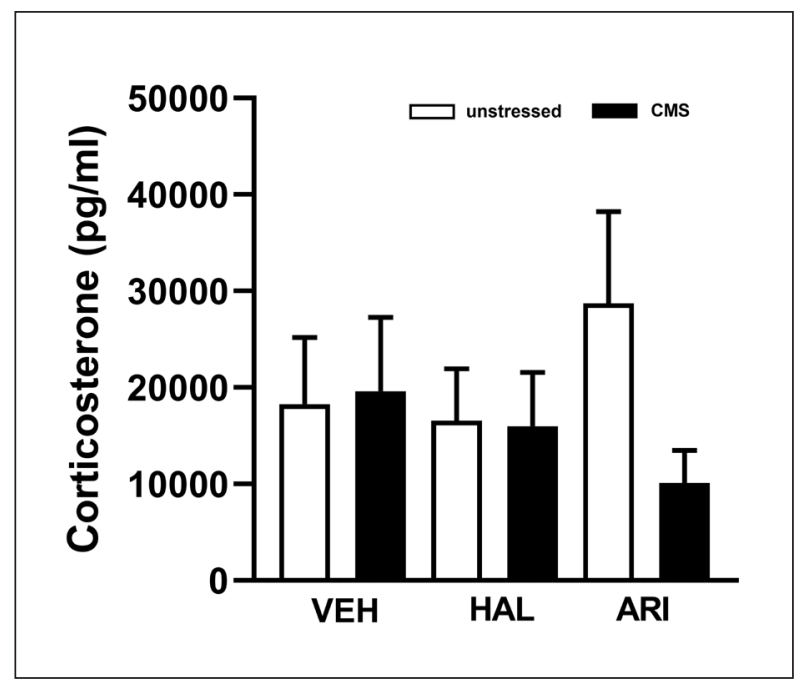

HIP - hippocampus; PFC - prefrontal cortex; VEH - vehicle. Figure 5. Plasma corticosterone (CORT) levels. Neither previous CMS nor HAL/ARI treatment affected the plasma CORT levels. Data are presented as the mean \pm SEM $(n=7-8$ per group). Abbreviations: ARI - aripiprazole; CMS - chronic mild stress; HAL - haloperidol.

sion; while in the HIP, the CMS elevated BDNF mRNA levels, but did not affect the GR mRNA ones. Notably, GR expression in the PFC was downregulated although no elevation in the plasma CORT level was seen. Previous studies have shown unchanged $\mathrm{BDNF}$ levels in the PFC and slightly reduced BDNF levels in the HIP two days after the CMS (SequeiraCordero et al. 2019). Other study has demonstrated significantly reduced BDNF mRNA levels in the whole HIP immediately after the CMS termination (Tornese et al. 2019) and the BDNF protein expression in the HIP has been shown to be declined in the unpredictable CMS even 4 weeks after its termination (Shen et al. 2019). Notably, the decrease in BDNF expression has been related only to the dentate gyrus and not the HIP CA region (Gronli et al. 2006). Decreased BDNF and GR expression in the PFC and the HIP, and elevated plasma CORT level has also been observed one week after CMS (Chen et al. 2016). The changes reported in most of the above-mentioned studies may differ from those demonstrated in the present study, especially in the HIP. However, it is important to notice that the time frame between CMS termination and the euthanasia of animals was shorter in most of the previous studies. The signature of the CMS has also been shown to be much prominent in the PFC in comparison with the HIP or the hypothalamus (Musaelyan et al. 2020). It cannot be also excluded that BDNF and GR downregulation in 
the PFC may be a delayed and/or persisting consequence of the CMS preconditioning. The PFC seems to be more sensitive to increased glucocorticoid levels during the CMS than the HIP, what might be associated with different long-term consequences during the recovery phase in the PFC-HIP formation.

No differences were found between VEH and CMS+VEH animals in the c-Fos expression in the PFC or the HIP. Previous studies have shown increased c-Fos levels after CMS (Westenbroek et al. 2003; Law et al. 2016); but again, the time between the CMS termination and the euthanasia of the animals was shorter than in our study. We assume that the CMS effect disappeared after two weeks of the recovery period. Other work has presented decreased c-Fos expression in the HIP 4 weeks after the CMS, but the effect of the CMS was different in the ventral and dorsal parts of the HIP (Elizalde et al. 2010). Since we did not investigate the HIP subregions, the possible CMS discrete effects on HIP cannot be evaluated in the present study.

The effects of HAL and ARI on BDNF and GR levels has been observed under basal conditions as well as after stress exposure in different brain regions (Dawson et al. 2001; Robbins et al. 2008; Luoni et al. 2014). In unstressed animals, only HAL suppressed BDNF and GR mRNA levels in the PFC. Previous data have shown that acute and subchronic HAL treatments may differently affect the BDNF immunoreactivity in the brain. While 3 -days of HAL administration decreased BDNF immunostaining in the PFC neurons and fibers, the subchronic (21 days) treatment led to a rebound in BDNF immunoreactivity in most of the cell bodies, but not fibers, in the HIP, the extended amygdala, and the ventral tegmental area (Dawson et al. 2001). Other study has shown that 90or 180-days of HAL treatment significantly reduced BDNF levels in the HIP and the striatum (Pillai and Mahadik 2006). Data concerning the impact of ARI on BDNF expression also differ. Six days after termination of 14-days of ARI treatment, no changes in BDNF levels have been detected in the HIP (Hudson et al. 2017). Repeated 21-days of ARI treatment has reduced the total BDNF mRNA levels in the ventral and dorsal HIP, while in the ventral HIP, up-regulated BDNF long 3-UTR isoform that is preferentially targeted towards dendrites has been detected (Luoni et al. 2014). HAL, which is characterized by a strong antagonism towards the dopamine D2 receptors, has a detrimental impact on BDNF expression, while ARI that besides a partial agonism at D2 receptors, is a multi-receptor drug that may not suppress BDNF expression (Luoni et al. 2014). Moreover, acute HAL administration has been shown to increase DA levels in the PFC and arcuate nucleus, but chronic HAL treatment decreased basal DA in PFC (Hernandez and Hoebel 1989). This might explain the suppressed BDNF mRNA levels in our study. ARI in lower dose has been shown to increase release of DA in the HIP and the PFC. However, in higher doses $(10 \mathrm{mg} / \mathrm{kg})$, it transiently decreased the DA cortical release ( $\mathrm{Li}$ et al. 2004). We assume that the missing response in BDNF mRNA level to ARI treatment may be associated with the fact that ARI besides blocking D2 receptors may also act via many other types of receptors. In the HIP, chronic HAL as well as ARI treatments suppressed BDNF gene expression stimulated by CMS. Following acute stress, ARI facilitated the translocation of the GR receptor to the nuclear compartment (as suggested by the increased nuclear/ cytosolic fraction ratio), where it may influence the regulation of different genes including the BDNF one (Luoni et al. 2014).

In the present study, only chronic HAL treatment increased the number of c-Fos cells in the HIP, but the CMS preconditioning reversed this effect. Chronic HAL treatment has been shown to increase c-Fos immunoreactivity in the caudate nucleus, the accumbens nucleus, the hippocampal CA1 area, and the dentate gyrus, but had no effect in the PFC (Sun et al. 1998; Collins et al. 2014), what is in accordance with the data of the present study. On the other hand, 14-days ARI treatment has been shown to increase c-Fos expression in the PFC, but the dose used $(3 \mathrm{mg} / \mathrm{kg})$ differed from that used in the present study (Hara et al. 2017), what may explain the discrepancy between these data. Previous CMS exposure suppressed the number of c-Fos immunoreactive cells in the PFC after both HAL and ARI treatment. In the HIP, the CMS-reduced number of c-Fos immunoreactive cells was detected only after HAL exposure.

The present data indicate that HAL in the dose of $1 \mathrm{mg} / \mathrm{kg}$ and ARI in the dose of $10 \mathrm{mg} / \mathrm{kg}$ did not modify the effect of the CMS preconditioning on the BDNF and GR mRNA levels in the PFC or the HIP. However, HAL seems to modify the CMS effect on the HIP activation, as it is indicated by the c-Fos immunohistochemical data.

\section{Acknowledgements}

The research was supported by grant of the Slovak Research and Development Agency (APVV-15-0037) and VEGA grant (2/0037/19) of the Slovak Academy of Sciences. 


\section{References}

Antoniuk S, Bijata M, Ponimaskin E, Wlodarczyk J. Chronic unpredictable mild stress for modeling depression in rodents: Meta-analysis of model reliability. Neurosci Biobehav Rev 99, 101-116, 2019.

Ayensu WK, Pucilowski O, Mason GA, Overstreet DH, Rezvani AH, Janowsky DS. Effects of chronic mild stress on serum complement activity, saccharin preference, and corticosterone levels in Flinders lines of rats. Physiol Behav 57, 165-169, 1995.

Chen J, Wang ZZ, Zuo W, Zhang S, Chu SF, Chen NH. Effects of chronic mild stress on behavioral and neurobiological parameters - Role of glucocorticoid. Horm Behav 78, 150-159, 2016.

Collins CM, Wood MD, Elliott JM. Chronic administration of haloperidol and clozapine induces differential effects on the expression of Arc and c-Fos in rat brain. J Psychopharmacol 28, 94-954, 2014.

Dawson NM, Hamid EH, Egan MF, Meredith GE. Changes in the pattern of brain-derived neurotrophic factor immunoreactivity in the rat brain after acute and subchronic haloperidol treatment. Synapse 39, 70-81, 2001.

De Santis M, Pan B, Lian J, Huang XF, Deng C. Different effects of bifeprunox, aripiprazole, and haloperidol on body weight gain, food and water intake, and locomotor activity in rats. Pharmacol Biochem Behav 124, 167-173, 2014.

Elizalde N, Garcia-Garcia AL, Totterdell S, Gendive N, Venzala E, Ramirez MJ, Del Rio J, Tordera RM. Sustained stress-induced changes in mice as a model for chronic depression. Psychopharmacology (Berl) 210, 393-406, 2010.

Fachinetto R, Burger ME, Wagner C, Wondracek DC, Brito VB, Nogueira CW, Ferreira J, Rocha JB. High fat diet increases the incidence of orofacial dyskinesia and oxidative stress in specific brain regions of rats. Pharmacol Biochem Behav 81, 585-592, 2005.

Fell MJ, Neill JC, Marshall KM. Effects of the classical antipsychotic haloperidol and atypical antipsychotic risperidone on weight gain, the oestrous cycle and uterine weight in female rats. Eur Neuropsychopharmacol 14, 385-392, 2004.

Froger N, Palazzo E, Boni C, Hanoun N, Saurini F, Joubert C, Dutriez-Casteloot I, Enache M, Maccari S, Barden N, Cohen-Salmon C, Hamon M, Lanfumey L. Neurochemical and behavioral alterations in glucocorticoid receptor-impaired transgenic mice after chronic mild stress. J Neurosci 24, 2787-2796, 2004.

Godsil BP, Kiss JP, Spedding M, Jay TM. The hippocampal-prefrontal pathway: the weak link in psychiatric disorders? Eur Neuropsychopharmacol 23, 1165-1181, 2013.

Gronli J, Bramham C, Murison R, Kanhema T, Fiske E, Bjorvatn B, Ursin R, Portas CM. Chronic mild stress inhibits BDNF protein expression and CREB activation in the dentate gyrus but not in the hippocampus proper Pharmacol Biochem Behav 85, 842-849, 2006.

Hara Y, Ago Y, Taruta A, Hasebe S, Kawase H, Tanabe W, Tsukada S, Nakazawa T, Hashimoto H, Matsuda T, Takuma K. Risperidone and aripiprazole alleviate prenatal valproic acid-induced abnormalities in behaviors and dendritic spine density in mice. Psychopharmacology (Berl) 234, 3217-3228, 2017.

Hernandez L, Hoebel BG. Haloperidol given chronically decreases basal dopamine in the prefrontal cortex more than the striatum or nucleus accumbens as simultaneously measured by microdialysis. Brain Res Bull 22, $763-769,1989$.

Hill MN, Hellemans KGC, Verma P, Gorzalka BB, Weinberg J. Neurobiology of chronic mild stress: parallels to major depression. Neurosci Biobehav Rev 36, 2085-2117, 2012.

Hudson R, Zhou Y, Leri F. The combination of escitalopram and aripiprazole: Investigation of psychomotor effects in rats. J Psychopharmacol 31, 1605-1614, 2017.

Jacobson L. Hypothalamic-pituitary-adrenocortical axis: neuropsychiatric aspects. Comp Physiol 4, 715-738, 2014.

Kompagne H, Bardos G, Szenasi G, Gacsalyi I, Harsing LG, Levay G. Chronic mild stress generates clear depressive but ambiguous anxiety-like behaviour in rats. Behav Brain Res 193, 311-314, 2008.

Law J, Ibarguen-Vargas Y, Belzung C, Surget A. Decline of hippocampal stress reactivity and neuronal ensemble coherence in a mouse model of depression. Psychoneuroendocrinology 67, 113-123, 2016.

Li Z, Ichikawa J, Dai J, Meltzer HY. Aripiprazole, a novel antipsychotic drug, preferentially increases dopamine release in the prefrontal cortex and hippocampus in rat brain. Eur J Pharmacol 493, 75-83, 2004.

Livak KJ, Schmittgen TD. Analysis of relative gene expression data using real-time quantitative PCR and the 2(-Delta Delta C(T)) Method. Methods 25, 402-408, 2001.

Luoni A, Fumagalli F, Racagni G, Riva MA. Repeated aripiprazole treatment regulates Bdnf, Arc and Npas4 expression under basal condition as well as after an acute swim stress in the rat brain. Pharmacol Res 80, 1-8, 2014. 
Mao QQ, Ip SP, Ko KM, Tsai SH, Che CT. Peony glycosides produce antidepressant-like action in mice exposed to chronic unpredictable mild stress: effects on hypothalamic-pituitary-adrenal function and brain-derived neurotrophic factor. Prog Neuropsychopharmacol Biol Psychiatry 33, 1211-1216, 2009.

Mulder R, Hamilton AH, Irwin L, Boyce P, Morris G, Porter R, Malhi G. Treating depression with adjunctive antipsychotics. Bipolar Disord Suppl 2, 17-24, 2018.

Musaelyan K, Yildizoglu S, Bozeman J, Du Preez A, Egeland M, Zunszain PA, Pariante CM, Fernandes C, Thuret S. Chronic stress induces significant gene expression changes in the prefrontal cortex alongside alterations in adult hippocampal neurogenesis. Brain Commun 2, fcaa153, 2020.

Musil R, Obermeier M, Russ P, Hamerle M. Weight gain and antipsychotics: a drug safety review. Expert Opin Drug Saf 14, 73-96, 2015.

Nibuya M, Takahashi M, Russell DS, Duman RS. Repeated stress increases catalytic TrkB mRNA in rat hippocampus. Neurosci Lett 267, 81-84, 1999.

Osacka J, Szelle Cernackova A, Horvathova L, Majercikova Z, Pirnik Z, Kiss A. Clozapine impact on c-Fos expression in mild stress preconditioned male rats exposed to a novelty stressor. J Neurosci Res 96, 1786-1797, 2018.

Pan Y, Wang FM, Qiang LQ, Zhang DM, Kong LD. Icariin attenuates chronic mild stress-induced dysregulation of the LHPA stress circuit in rats. Psychoneuroendocrinology 35, 272-283, 2010.

Parker KJ, Schatzberg AF, Lyons DM. Neuroendocrine aspects of hypercortisolism in major depression. Horm Behav 43, 60-66, 2003.

Palkovits M, Brownstein MJ. Maps and guide to microdissection of the rat brain. New York, Elsevier, 1-223, 1988.

Paxinos G, Watson C. The rat brain in stereotaxic coordinates. Academic Press, 2007.

Pillai A, Mahadik SP. Differential effects of haloperidol and olanzapine on the expression of erythropoietin and its receptor in rat hippocampus and striatum. J Neurochem 98, 1411-1422, 2006.

Pouzet B, Mow T, Kreilgaard M, Velschow S. Chronic treatment with antipsychotics in rats as a model for antipsychotic-induced weight gain in human. Pharmacol Biochem Behav 75, 133-140, 2003.

Robbins MJ, Critchlow HM, Lloyd A, Cilia J, Clarke JD, Bond B, Jones DNC, Maycox PR. Differential expression of IEG mRNA in rat brain following acute treatment with clozapine or haloperidol: a semi-quantitative RTPCR study. J Psychopharmacol 22, 536-542, 2008.

Sequeira-Cordero A, Salas-Bastos A, Fornaguera J, Brenes JC. Behavioural characterisation of chronic unpredictable stress based on ethologically relevant paradigms in rats. Sci Rep 9, 17403, 2019.

Shen J, Li Y, Qu C, Xu L, Sun H, Zhang J. The enriched environment ameliorates chronic unpredictable mild stressinduced depressive-like behaviors and cognitive impairment by activating the SIRT1/miR-134 signaling pathway in hippocampus. J Affect Disord 248, 81-90, 2019.

Skrede S, Ferno J, Vazquez MJ, Fjaer S, Pavlin T, Lunder N, Vidal-Puig A, Dieguez C, Berge RK, Lopez M, Steen VM. Olanzapine, but not aripiprazole, weight-independently elevates serum triglycerides and activates lipogenic gene expression in female rats. Int J Neuropsychopharmacol 15, 163-179, 2012.

Song L, Che W, Min-Wei W, Murakami Y, Matsumoto K. Impairment of the spatial learning and memory induced by learned helplessness and chronic mild stress. Pharmacol Biochem Behav 83, 186-193, 2006.

Sun YJ, Suzuki M, Kurachi T, Murata M, Kurachi M. Expression of Fos protein in the limbic regions of the rat following haloperidol decanoate. Brain Res 791, 125-136, 1998.

Tornese P, Sala N, Bonini D, Bonifacino T, La Via L, Milanese M, Treccani G, Seguini M, Ieraci A, Mingardi J, Nyengaard JR, Calza S, Bonanno G, Wegener G, Barbon A, Popoli M, Musazzi L. Chronic mild stress induces anhedonic behavior and changes in glutamate release, BDNF trafficking and dendrite morphology only in stress vulnerable rats. The rapid restorative action of ketamine. Neurobiol Stress 10, 100160, 2019.

Tyler MW, Zaldivar-Diez J, Haggarty SJ. Classics in Chemical Neuroscience: Haloperidol. ACS Chem Neurosci 8, 444-453, 2017.

Westenbroek C, Den Boer JA, Ter Horst GJ. Gender-specific effects of social housing on chronic stress-induced limbic Fos expression. Neuroscience 121, 189-199, 2003.

Wiborg O. Chronic mild stress for modeling anhedonia. Cell Tissue Res 354, 155-169, 2013.

Willner P. Validity, reliability and utility of the chronic mild stress model of depression: a 10-year review and evaluation. Psychopharmacology 134, 319-329, 1997.

Zhang Y, Gu F, Chen J, Dong W. Chronic antidepressant administration alleviates frontal and hippocampal BDNF deficits in CUMS rat. Brain Res 1366, 141-148, 2010. 